\title{
Posttetanic Potentiation at the Crayfish Neuromuscular Junction Is Dependent on Both Intracellular Calcium and Sodium Ion Accumulation
}

\author{
Rosel M. Mulkey and Robert S. Zucker \\ Department of Molecular and Cell Biology, University of California, Berkeley, California 94720
}

The fluorescent indicator fura-2 was used to measure cytoplasmic calcium in presynaptic terminals in the crayfish Procambarus clarkii under condltions that ralse intracellular sodium to examine whether sodium can elevate intracellular calcium concentration $\left(\left[\mathrm{Ca}^{2+}\right]_{i}\right)$ or prolong its efflux and thus influence the magnitude and duration of posttetanic potentiation (PTP).

Sodium was elevated in presynaptic terminals at rest by either (1) injection of sodium into the excitatory axon, (2) application of veratridine to open sodium channels, or (3) addition of ouabain to block $\mathrm{Na} / \mathrm{K}$ exchange, with $\left[\mathrm{Ca}^{2+}\right]_{i}$ increasing by either 430,400 , or $180 \mathrm{~nm}$, respectively. Intracellular calcium concentration increased only when external calcium was present, indicating that calcium influx occurred through $\mathrm{Na} / \mathrm{Ca}$ exchange. Additionally, ouabain enhanced excitatory junctional potentials (EJPs) eightfold. Elevation of sodium using a high-frequency stimulation in zero-calcium

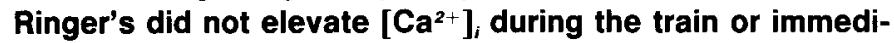
ately afterward when calcium-containing Ringer's was reintroduced. This indicates that a physiological sodium load does not release calcium from internal stores or reverse $\mathrm{Na}$ / $\mathrm{Ca}$ exchange to levels where $\left[\mathrm{Ca}^{2+}\right]_{i}$ accumulation is detectable.

We examined the ability of sodium to interfere with calcium efflux from presynaptic terminals by loading boutons with both sodium and calcium or calcium alone using high-potassium depolarization. Elevation of internal sodium slowed calcium efflux from the terminal (12.3 min) compared to calcium removal without a sodium load $(4.0 \mathrm{~min})$. When sodium loading was increased during a tetanus by application of ouabain, the time constants for decay of EJP potentiation, $17.3 \mathrm{~min}$, and for $\left[\mathrm{Ca}^{2+}\right], 35 \mathrm{~min}$, were longer than control values, $4.4 \mathrm{~min}$ and $\mathbf{5 . 8} \mathrm{min}$, respectively. In addition, using lithium to inhibit the efflux of calcium by $\mathrm{Na} / \mathrm{Ca}$ exchange following a PTP-inducing train also lengthened the decay of $\left[\mathrm{Ca}^{2+}\right]_{i}$ to $15.7 \mathrm{~min}$. Intracellular sodium accumulation in presynaptic terminals slows the efflux of calcium through $\mathrm{Na}$ / Ca exchange, and may therefore augment and prolong PTP.

Received Oct. 7, 1991; revised May 14, 1992; accepted June 5, 1992.

We thank Dr. Kerry Delaney and Dr. David Tank, AT\&T Bell Laboratories, Murray Hill, NJ, for sharing and allowing us to use their unpublished SBFI data, in addition to Dr. Delaney's valuable discussion. We also thank Russell English for expert technical assistance. This work was supported by NIH Research Grant NS 15114.

Correspondence should be addressed to Dr. Rosel M. Mulkey, Department of Psychiatry, LPPI, Box 0984, University of California, San Francisco, CA 94143. Copyright (C) 1992 Society for Neuroscience $0270-6474 / 92 / 124327-10 \$ 05.00 / 0$
Transmitter release is dependent on the influx of extracellular calcium into presynaptic terminals (Katz, 1969). At the neuromuscular junction (NMJ) of the crayfish opener muscle, transmitter release shows many forms of frequency-dependent enhancement. Stimulation of the excitor axon for a few seconds at a frequency greater than $1 \mathrm{~Hz}$ will produce enhancement of the excitatory junctional potential (EJP) amplitude that decays in less than a second. This enhancement is termed facilitation and is presumably due to a residual increase in intracellular calcium (Atwood and Wojtowicz, 1986; Zucker, 1989). A longer, more robust stimulation, that is, $20-33 \mathrm{~Hz}$ for $5-10 \mathrm{~min}$, will producc two different kinds of long-term enhancement: posttetanic potentiation (PTP), which decays in minutes, and longterm facilitation (LTF), which lasts for tens of minutes to hours. PTP has been linked to the entry and accumulation of calcium and/or sodium ions into the presynaptic terminals during neural activity (Wojtowicz and Atwood, 1988). A direct measurement of $\left[\mathrm{Ca}^{2+}\right]_{i}$ following a PTP-inducing train at the crayfish NMJ, using the fluorescent indicator fura-2, has shown that $\left[\mathrm{Ca}^{2+}\right]_{i}$ decays at the same rate as PTP (Delaney et al., 1989), suggesting that $\left[\mathrm{Ca}^{2+}\right]_{i}$ is important for this process. In addition, there has been strong evidence to suggest that intraterminal sodium $\left(\left[\mathrm{Na}^{+}\right]_{i}\right)$ accumulation also plays an important role. Atwood et al. (1975) showed at the crayfish NMJ that a lowered external sodium concentration reduced PTP, whereas conditions that led to increased sodium loading through inhibition of $\mathrm{Na} / \mathrm{K}$ exchange prolonged PTP. Other investigators confirmed that elevating $\left[\mathrm{Na}^{+}\right]_{i}$ by similar methods augmented PTP, both at the frog (Rahamimoff et al., 1978; Lev-Tov and Rahamimoff, 1980; Misler and Hurlbut, 1983; Misler et al., 1987) and rat NMJ (Nussinovitch and Rahamimoff, 1988). Sodium injected directly into presynaptic terminals of the crayfish axon (Wojtowicz and Atwood, 1985) and the squid giant synapse (Charlton and Atwood, 1977) also enhanced transmitter release. Pharmacological agents used to raise $\left[\mathrm{Na}^{+}\right]_{i}$, such as veratridine and monensin, consistently increased transmitter release at both invertebrate (Atwood et al., 1983; Finger and Martin, 1987) and vertebrate NMJ (Meiri et al., 1981).

Various mechanisms by which elevation of $\left[\mathrm{Na}^{+}\right]_{i}$ could enhance transmitter release have been proposed. The first possibility is that internal sodium ions could have a direct effect on transmitter release. Alternatively, sodium ions could increase $\left[\mathrm{Ca}^{2+}\right]_{i}$ by release of calcium from intracellular stores, by entry from the external medium through $\mathrm{Na} / \mathrm{Ca}$ exchange, or by slowing removal of accumulated calcium because of a reduction in the sodium gradient that drives $\mathrm{Na} / \mathrm{Ca}$ exchange.

To test these possibilities directly, we have used the fluores- 
cent indicator fura- 2 to measure cytoplasmic $\left[\mathrm{Ca}^{2+}\right]_{i}$ in presynaptic terminals of crayfish opener muscle under conditions where intracellular sodium was elevated by pharmacological and physiological methods. Simultaneous recordings of EJPs and $\left[\mathrm{Ca}^{2+}\right]_{i}$ measurements were acquired during sodium elevation in some experiments. The effect of sodium elevation on resting $\left[\mathrm{Ca}^{2+}\right]_{i}$ was measured along with its effect on the decline of $\left[\mathrm{Ca}^{2+}\right]_{i}$ during decay of PTP. We have attempted to determine whether intracellular sodium elevation during tetanic stimulation influences the posttetanic decay of $\left[\mathrm{Ca}^{2+}\right]_{i}$ that lasts for minutes and, if so, by which mechanism it operates.

A preliminary account of these experiments has appeared in Mulkey and Zucker (1991b) and in Zucker et al. (1991).

\section{Materials and Methods}

Dye injection. All experiments were performed on the opener muscle of the first walking leg of crayfish, Procambarus clarkii, using animals measuring 2-2.5 inches. Viewing the preparation through a Nikon CF-E $10 \times$ long-working-distance air objective $(5.2 \mathrm{~mm})$, the excitatory axon was penetrated near the $\mathrm{Y}$-branch with standard-wall glass microelectrodes $(40 \mathrm{M} \Omega$ with $3 \mathrm{M} \mathrm{KCl})$ that were filled with fura-2 $(22 \mathrm{~mm})$ pentapotassium salt (Molecular Probes, Eugene, OR) in $200 \mathrm{~mm} \mathrm{KCl}$. Fura-2 was iontophoresed into the excitatory axon by injecting 10-12 $\mathrm{nA}$ of hyperpolarizing current for approximately $30 \mathrm{~min}$. The excitor action potential was continuously monitored intracellularly during the filling in response to extracellular stimulation of the nerve at $0.5 \mathrm{~Hz}$. The intensity of the fluorescence was monitored in the presynaptic terminals during the injection to prevent overfilling, as fura- 2 is a calcium buffer that can alter the time course and magnitude of calcium transients in neurons when present at high concentrations (Kao and Tsien, 1988). The final concentration of fura- 2 in the boutons was estimated by comparing the intensity of fluorescence of a $50 \mu \mathrm{M}$ fura- 2 solution in a $20-\mu \mathrm{m}$-pathlength cuvette to the intensity in presynaptic terminals having a pathlength of approximately $5-10 \mu \mathrm{m}$. The fluorescent intensity in terminals was about double that in the cuvette, suggesting that the concentration in the boutons was about $200 \mu \mathrm{M}$. After filling with fura-2, the injection electrode was gently removed in preparation for imaging.

Electrophysiology. The excitatory axon was dissected from the meropodite segment and placed in a plastic suction electrode for stimulation. While viewing the preparation through a Zeiss $40 \times$ water immersion objective (1.6 mm working distance), intracellular electrodes containing $3 \mathrm{M} \mathrm{KCl}(10 \mathrm{M} \Omega$ ) were placed in muscle fibers onto which imaged terminals synapsed (if possible) or in adjacent fibers for recording FJPs. In the PTP experiments, following the high-frequency train, the excitor axon was stimulated at $1 \mathrm{~Hz}$ and EJPs were acquired and averaged using a Nicolet 4094 digital oscilloscope during successive $1 \mathrm{~min}$ intervals until EJPs returned to control values. In some experiments, LTF was observed: EJPs did not return to their pretetanic level for the time measured (up to $1 \mathrm{hr}$ ). Averaged EJPs were stored on floppy disks for later analysis. Individual EJPs obtained during shorter trains were recorded with a Gould chart recorder. An extracellular electrode (25$50 \mu \mathrm{m}$ inside diameter) was positioned on a distal axonal branch to record the nerve field potential during high-frequency stimulation in zero-calcium solutions to ensure action potential invasion.

Injection of sodium and potassium ions. Sodium ions were injected into the excitatory axon with standard-wall glass microelectrodes (40 $\mathrm{M} \Omega$ ) filled with $3 \mathrm{M} \mathrm{NaCl}$ and $0.3 \mathrm{M} \mathrm{KCl}$, using 5-10 nA depolarizing current. $\mathrm{KCl}$ was included in the $\mathrm{NaCl}$ pipette, as it improved the recording characteristics of the electrodes so the action potential could be monitored throughout the injection. Potassium ions were injected in the same manner, but with microelectrodes filled with $3 \mathrm{M} \mathrm{KCl}$.

Solutions. Normal Van Harraveld's solution contained (in mM) 195 $\mathrm{NaCl}, 13.5 \mathrm{CaCl}_{2}, 5.4 \mathrm{KCl}, 2.6 \mathrm{MgCl}_{2}$, and $10 \mathrm{Na}$-HEPES at pH 7.4 . The EGTA Ringer's contained (in mM) $185 \mathrm{NaCl}, 5.4 \mathrm{KCl}, 30 \mathrm{MgCl}_{2}$, $2 \mathrm{Na}_{2}$ EGTA, and $10 \mathrm{Na}-\mathrm{HEPES}$ at pH 7.4. Cobalt Ringer's contained $\mathrm{CoCl}_{2}$ substituted for $\mathrm{CaCl}_{2}$ (13.5 mM), along with (in mM) $175 \mathrm{NaCl}$, $5.4 \mathrm{KCl}, 30 \mathrm{MgCl}_{2}$, and $10 \mathrm{Na}-\mathrm{HEPES}$ at $\mathrm{pH}$ 7.4. In lithium Ringer's lithium replaced sodium and Na-HEPES was reduced from 10 to $5 \mathrm{~mm}$. Zero-sodium saline contained choline chloride instead of $\mathrm{NaCl}$, plus (in mM) $13.5 \mathrm{CaCl}_{2}, 2.6 \mathrm{MgCl}_{2}$, and $6 \mathrm{~K}$-HEPES. Zero-sodium, zero-calcium saline consisted of choline chloride substituted for $\mathrm{NaCl}$, plus (in
mM) $16.1 \mathrm{MgCl}_{2}, 6 \mathrm{~K}$-HEPES, and $2 \mathrm{~K}_{2}$ EGTA at pH 7.4. The highpotassium saline solutions contained $40 \mathrm{mM} \mathrm{KCl}$, with choline chloride substituted for $\mathrm{NaCl}$ in the zero-sodium, high-potassium saline. Veratridine was obtained from Sigma, and stock solutions were made by dissolving the drug in $0.1 \mathrm{~N} \mathrm{HCl}$ and storing it in the freezer. Final concentrations were obtained by dissolving veratridine in the appropriate saline. Ouabain (Aldrich) was made up fresh daily by dissolving it in the appropriate saline solution at its final concentration.

The temperature of the preparation was kept at $18 \pm 2^{\circ} \mathrm{C}$ with a stagemounted Peltier devicc. A gravity perfusion system controlled by a solenoid four-way valve (General Valve, series 18, Fairfield, NJ) was used to switch between normal and modified salines. An inflow was positioned above the surface of the opener muscle, and solutions flowed under the $40 \times$ water immersion lens. However, to ensure complete removal of calcium from the bath, the objective was lifted out of the bath and the surface washed vigorously with a syringe having a $1-\mathrm{mm}$ diameter plastic tube attached to the tip, while also continuing to perfuse with the gravity system. A perfusion time of about $10 \mathrm{~min}$ in cobalt Ringer's was needed to eliminate calcium influx during a high-frequency train. With zero-calcium EGTA, perfusion for 45-60 min with repeated vigorous washing was usually required.

Imaging of presynaptic terminals. Individual presynaptic terminals were imaged using a $40 \times$ Zeiss water immersion lens and a Nikon Optiphot upright compound microscope cquipped with a silicon intensified target (SIT) camera (Dage MTI, model 66). Bandpass filters of $350 \pm 10 \mathrm{~nm}$ and $385 \pm 5 \mathrm{~nm}$ (Omega Optical, Brattleboro, VT) were used to pass the selective excitation wavelengths for fura-2. The filters were mounted on a wheel driven by a computer-controlled stepper motor with an electronic shutter (also computer driven) placed proximally in the light path. A dichroic mirror $(450 \mathrm{~nm})$ separated the excitation and emission wavelengths, and a barrier filter $(510 \pm 10 \mathrm{~nm})$ passed only the peak emission wavelength, reducing interference from autofluorescence. Before each experiment, images for both the camera background (which includes tube dark current, optical autofluorescence, etc.) and tissue background were taken, along with a shading image, which corrects for the variations in intensity of the two excitation wavelengths over the field of view. A tissue background consisted of an image of a muscle fiber whose fluorescence was similar to that of the muscle fiber onto which the imaged terminals made synapses. An image processor (Gould FD 5000, Fremont, CA) automatically subtracted each background and shading correction before displaying an image. Sequential 350 and $385 \mathrm{~nm}$ images were stored on an optical disk recorder (Panasonic TQ-2028F, Secaucus, NJ). The image processor, optical disk recorder, filter wheel, and shutter were under the control of a Scientific Microsystems SMS 1000 computer (Mountain View, CA), using software written by Dr. Roger Tsien (Pharmacology Department, University of California at San Diego).

Ratios were acquired using averages of 32 or 64 frames at each excitation wavelength with the SIT camera. In vivo calibrations to estimate the $350: 385 \mathrm{~nm}$ fluorescence ratios at saturated calcium $\left(R_{\max }\right)$ and at zero-calcium $\left(R_{\min }\right)$ were done using $50 \mu \mathrm{M}$ digitonin (obtained from Sigma and dissolved in distilled water) added to normal saline or zerocalcium saline containing $10 \mathrm{mM} \mathrm{Na} \mathrm{NGTA}_{2}$. An $R_{\min }$ was hard to achieve, as the intracellular calcium concentration of the presynaptic terminal increased in the application of digitonin. It is possible the calcium stores from muscle were leaking into the external medium, raising the extracellular calcium concentration and leading to an increase in intracellular calcium in the terminals. From experiments in which the preparation was soaked in an EGTA Ringer's for spproximately $50 \mathrm{~min}$, we found $R_{\min }$ to be about 0.8 . It was possible to determine $R_{\max }$ using $50 \mu \mathrm{M}$ digitonin in normal saline. This is a rather high concentration of digitonin (Negulescu and Machen, 1990), but lower concentrations were not effective in raising intracellular calcium concentration. $R_{\max }$ was measured as 19. A dissociation constant for fura- 2 could not be calculated from these in vivo methods, as the possibility that calcium leaks from muscle fibers would raise the cxtcrnal calcium to unknown values and give an inaccurate value. Therefore, the $K_{D}$ of fura- 2 in crayfish axoplasm was estimated at $865 \mathrm{~nm}$ by measuring the ratio of fluorescence to excitation at 350 and $385 \mathrm{~nm}$ of $50 \mu \mathrm{M}$ fura-2 mixed in a solution resembling crayfish cytoplasm $(250 \mathrm{~mm}$ K-D-gluconate, $15 \mathrm{~mm} \mathrm{NaCl}$, $15 \mathrm{~mm} \mathrm{~K}$-HEPES at pH 7.02). The calcium was buffered to $500 \mathrm{~nm}$

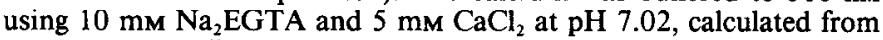
the measured affinity of EGTA (Grynkiewicz et al., 1985). Pairs of ratioed images obtained with 350 and $385 \mathrm{~nm}$ excitation were used to calculate intracellular calcium concentration from Equation 5 of Grynkiewicz et al. (1985) using the above values for $R_{\min }, R_{\max }$, and $K_{D}$. 
Movement of the preparation due to muscle contraction was often a problem during or following PTP-inducing stimulation, especially in the ouabain-containing solutions. Movement during acquisition of image pairs will give incorrect values for $\left[\mathrm{Ca}^{2+}\right]_{i}$. Therefore, in experiments in which high-frequency stimulation was used, the preparation was stabilized by gluing the distal two segments of the shell to the Sylgard surface of the recording dish using a cyanoacrylate glue (Histoacryl Blau, Tri Hawk Industries, Montreal, Canada).

Data analysis. To determine $\left[\mathrm{Ca}^{2+}\right]_{i}$ from stored images, circular masks, encompassing 100-300 pixels, were positioned over terminals and the $\left[\mathrm{Ca}^{2+}\right]_{i}$ was spatially averaged.

Time constants were calculated for the decline in $\left[\mathrm{Ca}^{2+}\right]_{i}$ and EJPs following PTP-inducing trains in both normal and oubain solutions and tested for statistical significance using a paired $t$ test. Similar statistical tests were done on calculated time constants for $\left[\mathrm{Ca}^{2+}\right]_{i}$ decay in control versus lithium Ringer's following PTP-inducing trains.

\section{Results}

\section{Elevation of $\left[\mathrm{Na}^{+}\right]_{\mathrm{i}}$ in the axon and presynaptic terminals} elevates $\left[\mathrm{Ca}^{2+}\right]$;

It is thought that elevation of sodium ions intracellularly can lead to an increase in $\left[\mathrm{Ca}^{2+}\right]_{i}$ (Rahamimoff et al., 1980). There are two ways the sodium ion accumulation could elevate $\left[\mathrm{Ca}^{2+}\right]_{i}$ : (1) by releasing calcium from internal stores, or (2) by calcium entering from the external medium through reversal or reduced extrusion of $\mathrm{Na} / \mathrm{Ca}$ exchange. To test these two possibilities, we chose to elevate intracellular sodium ions and see what effect this had on the $\left[\mathrm{Ca}^{2+}\right]_{i}$. To elevate the $\left[\mathrm{Na}^{+}\right]_{i}$, three different methods were used. The $\left[\mathrm{Na}^{+}\right]_{i}$ was raised either (1) by injection of sodium ions directly from a microelectrode that had been inserted into the excitatory axon, or (2) by using the drug veratridine, which shifts the activation curve for sodium channels such that they are partially open at resting membrane potentials (Catterall, 1980), or (3) by eliminating sodium extrusion by blocking $\mathrm{Na} / \mathrm{K}$ exchange with ouabain.

Figure 1 shows an experiment in which sodium ion injection into the excitatory axon led to an increase of $\left[\mathrm{Ca}^{2+}\right]_{i}$ in the axon by $210 \mathrm{~nm}$. Intracellular calcium concentration was measured in the excitatory axon $100-150 \mu \mathrm{m}$ from the injection electrode. The electrode was placed in the proximal axon, where it is the largest in diameter, to ensure success of multiple penetrations with minimal damage. Since most presynaptic terminals synapse onto muscle fibers more distally from the proximal axon, imaging of these terminals becomes more difficult with a microelectrode inserted into the axon, and injected sodium might not reach distant terminals. Therefore, we imaged $\left[\mathrm{Ca}^{2+}\right]_{i}$ near the injection electrode. The result in Figure 1 is typical of seven preparations in normal Ringer's showing a $\left[\mathrm{Ca}^{2+}\right]_{i}$ rise in the axon having a mean \pm SE equal to $430 \pm 80 \mathrm{nM}$. Upon perfusion of the preparation with an EGTA Ringer's, containing no added calcium, $2 \mathrm{mM} \mathrm{Na} 2 \mathrm{EGTA}$, and $30 \mathrm{mM} \mathrm{MgCl}_{2}$, a similar injection of sodium ions (using the same electrode and current) did not increase the $\left[\mathrm{Ca}^{2+}\right]_{i}$. Two of the four sodium injection experiments performed in zero-calcium saline were done in a cobalt Ringer's (cobalt substituted for calcium). In some preparations, the $\left[\mathrm{Ca}^{2+}\right]_{i}$ increased slightly $(11.0 \pm 7.0 \mathrm{nM} ; N=4)$ in either a cobalt or an EGTA Ringer's, which is most likely due to an inadequate wash in zero-calcium Ringer's. Perfusion with zerocalcium Ringer's was difficult to do satisfactorily, as the electrode inserted in the axon was not always stable throughout a vigorous perfusion. Following the sodium ion injection, the $\mathrm{NaCl}$ electrode was gently removed and a microelectrode containing $3 \mathrm{M} \mathrm{KCl}$ was inserted into the axon to ensure that the injection of depolarizing current was not admitting calcium ions by opening voltage-dependent calcium channels. A potassium ion in-

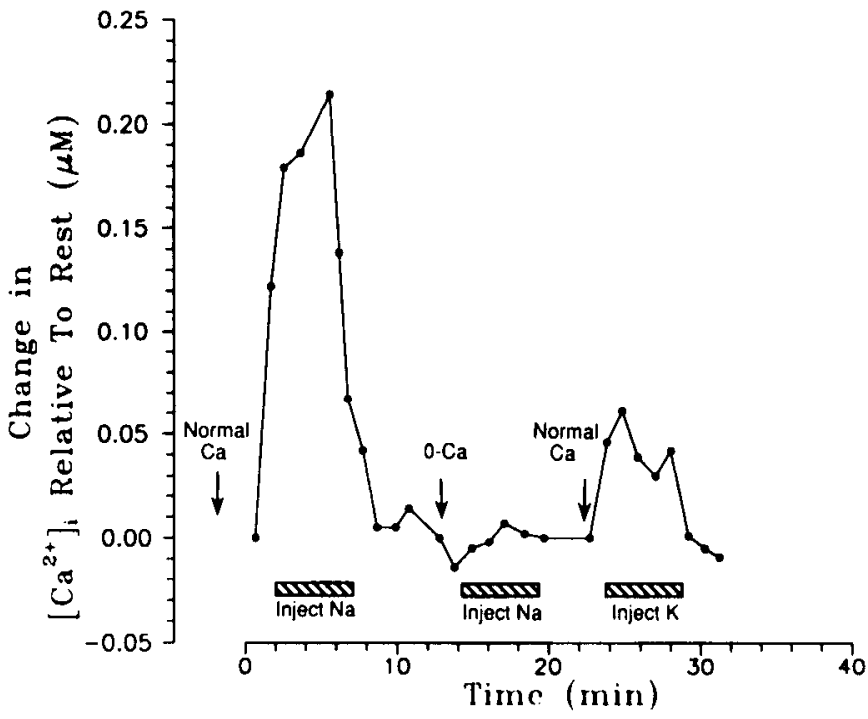

Figure 1. Effects of sodium and potassium injection on $\left[\mathrm{Ca}^{2+}\right]_{i}$ in a normal and calcium-free Ringer's. In normal Ringer's, sodium ions were injected into the excitatory axon using $+10 \mathrm{nA}$ current with the injection time depicted by the hatched bar. The $\left[\mathrm{Ca}^{2}\right]_{i}$ rose by $210 \mathrm{~nm}$ in the axon in response to the increase in $\left[\mathrm{Na}^{+}\right]_{i}$. The $\left[\mathrm{Ca}^{2+}\right]_{i}$ returned to preinjection values when the injection current was halted. The preparation was then bathed in a zero-calcium EGTA solution, and sodium ions were again injected using $+10 \mathrm{nA}$ current. There was no observed increase in $\left[\mathrm{Ca}^{2+}\right]_{i}$. Calcium-containing Ringer's was added, and potassium ions were subsequently injected into the same area of the excitatory axon as the sodium ions, using $+10 \mathrm{nA}$ of current. The $\left[\mathrm{Ca}^{2+}\right]_{i}$ rose by $40 \mathrm{~nm}$ and returned to its resting value when the current was stopped.

jection control was done in all seven experiments. In Figure 1, the injection of potassium ions using $+10 \mathrm{nA}$ current elevated $\left[\mathrm{Ca}^{2+}\right]_{i}$ by $40 \mathrm{nM}$ (mean $\pm \mathrm{SE}, 130 \pm 30 \mathrm{nM} ; N=7$ ). In some preparations, the potassium injection did elevate $\left[\mathrm{Ca}^{2+}\right]_{i}$, but in all seven preparations the sodium injection elevated $\left[\mathrm{Ca}^{2+}\right]_{i}$ to substantially greater values (between 1.5 and 13 times greater effect). These results suggest that sodium ion accumulation in the excitatory axon can elevate $\left[\mathrm{Ca}^{2+}\right]_{i}$ in the axon, but only when external calcium is present. Therefore, a localized high concentration of intracellular sodium ions probably increases $\left[\mathrm{Ca}^{2+}\right]_{i}$ by reversal of $\mathrm{Na} / \mathrm{Ca}$ exchange with no indication of any release of calcium from internal stores.

Veratridine, at doses $(10-100 \mu \mathrm{M})$ used by previous investigators (Finger and Martin, 1987; Martin and Finger, 1988), is known to depolarize the axonal membrane to levels above that needed to activate voltage-gated calcium channels (Ohta et al., 1973; Wojtowicz and Atwood, 1984). When $\left[\mathrm{Ca}^{2+}\right]$, was measured in the presence of veratridine $(10-100 \mu \mathrm{M})$ in normal saline, the $\left[\mathrm{Ca}^{2+}\right]_{i}$ increased to $4-10 \mu \mathrm{M}$. In order to test the possibility intracellular sodium ion accumulation via open sodium channels leads to $\left[\mathrm{Ca}^{2+}\right]_{i}$ elevation either by release of calcium from internal stores or $\mathrm{Na} / \mathrm{Ca}$ exchange, lower doses of veratridine had to be used. Veratridine at doses of $0.5-1 \mu \mathrm{M}$ has been shown to depolarize crayfish axon approximately $2-6 \mathrm{mV}$ (Ohta et al., 1973). When axonal membrane voltage was measured during application of veratridine at $0.5 \mu \mathrm{M}$, the axon depolarized 4-5 $\mathrm{mV}$ and the $\left[\mathrm{Ca}^{2+}\right]_{i}$ increased to about $3 \mu \mathrm{M}$. Using high-potassium saline solutions to depolarize the presynaptic membrane uniformly, Delaney et al. (1991) have shown in crayfish that membrane depolarizations of 13-14 $\mathrm{mV}$ in the axon result in $\left[\mathrm{Ca}^{2+}\right]_{i}$ accumulation between 20 and $40 \mathrm{nM}$ in the presynaptic terminals, with depolarizations around $17-19 \mathrm{mV}$ 


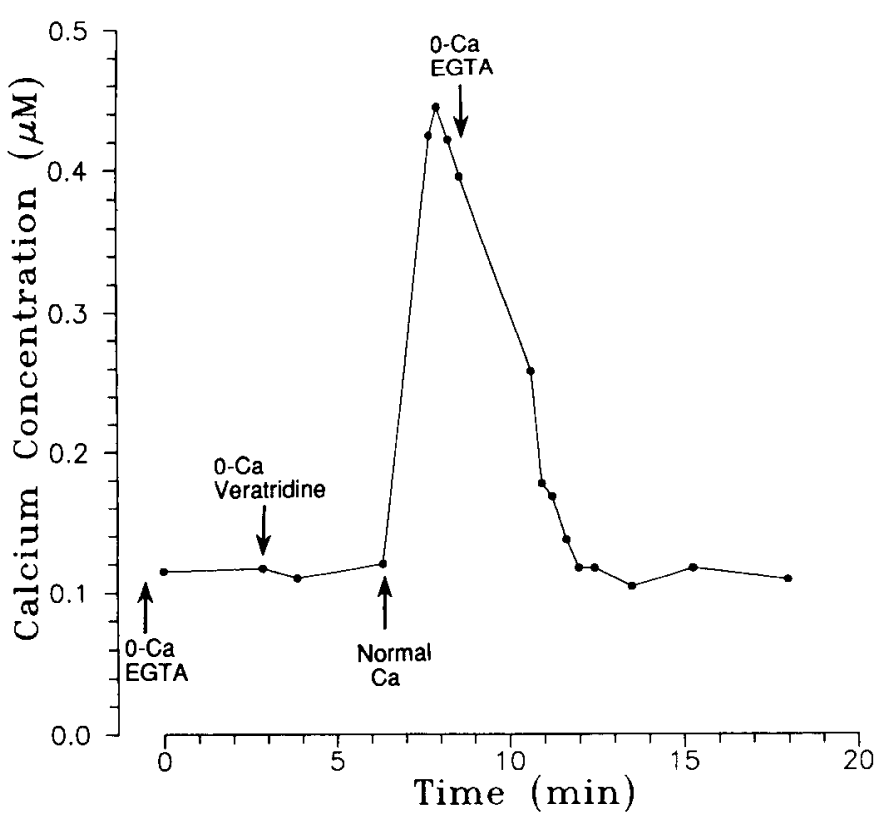

Figure 2. Effects of veratridine on $\left[\mathrm{Ca}^{2+}\right]$, in a calcium-free and normal Ringer's. The preparation was bathed in a zero-calcium EGTA Ringer's prior to veratridine application. Zero-calcium Ringer's containing 0.5 $\mu_{M}$ veratridine was added at the arrow and produced no measurable change in $\left[\mathrm{Ca}^{2+}\right]_{i}$. A calcium-containing Ringer's was added approximately $3 \mathrm{~min}$ later, and $\left[\mathrm{Ca}^{2+}\right]_{i}$ rose by $320 \mathrm{~nm}$. Washing in zero-calcium EGTA Ringer's brought the $\left[\mathrm{Ca}^{2+}\right]_{i}$ back to the resting value.

increasing $\left[\mathrm{Ca}^{2+}\right]_{i}$ sharply. Therefore, at low doses of veratridine, membrane depolarizations of 4-5 $\mathrm{mV}$ are probably not sufficient to activate enough voltage-gated calcium channels to lead to measurable $\left[\mathrm{Ca}^{2+}\right]_{i}$ accumulation.

Figure 2 shows the effect of $0.5 \mu \mathrm{M}$ veratridine in an EGTA Ringer's followed by a rinse in normal saline that contained calcium. Veratridine in a zero-calcium external medium did not increase $\left[\mathrm{Ca}^{2+}\right]_{i}$ in four preparations, and in three preparations the $\left[\mathrm{Ca}^{2+}\right]_{i}$ increased slightly, accounting for the variation recorded in the means ( $30 \pm 10 \mathrm{~nm} ; 14$ terminals in seven preparations, designated $N-14,7$ ). As mentioned previously, effective perfusion in zero-calcium saline was not achieved in all experiments, even though the preparation was soaked in EGTA Ringer's for 40-60 min. Veratridine does, however, increase $\left[\mathrm{Ca}^{2+}\right]_{i}$ when calcium was present in the external medium. As shown in Figure 2, $\left[\mathrm{Ca}^{2+}\right]_{i}$ increased to $440 \mathrm{~nm}$ from a resting value of $120 \mathrm{nM}$, showing a $320 \mathrm{~nm}$ increase in $\left[\mathrm{Ca}^{2+}\right]_{i}$, with a mean increase of $400 \pm 30 \mathrm{nM}, N=14,7$.

To test whether calcium ions were going through sodium channels activated by veratridine, we measured $\left[\mathrm{Ca}^{2+}\right]_{i}$ in a saline solution in which choline was substituted for sodium. The $\left[\mathrm{Ca}^{2+}\right]_{i}$ did not increase significantly in the veratridine mixture containing no sodium ions $(15.0 \pm 6.0 \mathrm{nM} ; N=8,5)$, but when sodium ions were added, the $\left[\mathrm{Ca}^{2+}\right]_{i}$ increased to $4.8 \pm 1.2 \mu \mathrm{M}$ $(N=8,5)$. In these experiments, veratridine concentrations of $1.0-100 \mu \mathrm{M}$ were used. These results suggest that elevation of the $\left[\mathrm{Na}^{\prime}\right]_{i}$, by means of veratridine application at $0.5-1.0 \mu \mathrm{M}$, increases $\left[\mathrm{Ca}^{2+}\right]_{i}$ most likely through an effect on $\mathrm{Na} / \mathrm{Ca}$ exchange.

Ouabain, at a dose of $0.5 \mathrm{~mm}$, increased the resting $\left[\mathrm{Ca}^{2+}\right]_{i}$ in presynaptic terminals by $180 \pm 30 \mathrm{nM}(N=12,8)$, with a 30-40 min delay between ouabain application and the increase in $\left[\mathrm{Ca}^{2+}\right]_{i}$. This delay in ouabain's action has previously been reported in reference to transmitter release at the frog NMJ (Bakcr and Crawford, 1975), and it was suggested this reflected the slow binding time of ouabain to the $\mathrm{Na} / \mathrm{K}$ exchanger, as Baker and Crawford reported no delay in the increased frequency of miniature endplate potentials (MEPPs) when a potassium-free medium was used to block $\mathrm{Na} / \mathrm{K}$ exchange. However, if low-frequency stimulation was given in the presence of ouabain, this $30-40 \mathrm{~min}$ delay could be shortened slightly, presumably by increasing the sodium entry, as also observed by Baker and Crawford (1975). K. R. Delaney and D. W. Tank (unpublished observations) measured $\left[\mathrm{Na}^{+}\right]_{i}$ in crayfish presynaptic terminals using the ratiometric fluorescent dye SBFI in the presence of $5 \mathrm{~mm}$ ouabain. The absolute value for $\left[\mathrm{Na}^{+}\right]_{i}$ in crayfish presynaptic terminals is not known from the SBFI (sodium-binding benzofuran isophthalate) data, because reliable calibration data were not obtained. They showed $\left[\mathrm{Na}^{+}\right]_{i}$ accumulation occurred within minutes of ouabain application, but $\left[\mathrm{Ca}^{3+}\right]_{i}$ accumulation took $30-40 \mathrm{~min}$ to occur, suggesting that this $30-40 \mathrm{~min}$ delay in calcium rise was not due to binding of ouabain to the pump but the time it took for the sodium accumulation to lead to $\left[\mathrm{Ca}^{2+}\right]_{i}$ accumulation.

Ouabain $(0.5 \mathrm{~mm})$ enhanced EJPs by $8.2 \pm 2.7$ times (eight preparations) when stimulating at frequencies of $1-10 \mathrm{~Hz}$. Since ouabain increased EJP amplitude more than expected for a 180 nM increase in $\left[\mathrm{Ca}^{21}\right]_{i}$ (Delaney et al., 1989), we looked for an effect of ouabain on calcium influx during action potentials. Figure 3 shows the resting $\left[\mathrm{Ca}^{2+}\right]_{i},\left[\mathrm{Ca}^{2+}\right]_{i}$ during $5 \mathrm{~Hz}$ stimulation, and the accompanying EJPs (consisting of the mean of $20 \mathrm{EJP}$ amplitudes at $5 \mathrm{~Hz}$ ) in a preparation bathed in normal saline, followed by the addition of ouabain and finally the washout of the drug. Ouabain increased the resting level of calcium in this preparation by $300 \mathrm{~nm}$ (Fig. 3) along with a 15-fold enhancement in EJP amplitude. There was a very slight increase in calcium accumulation that occurred during a $5 \mathrm{~Hz}$ stimulation in ouabain (20-50 nM), but this was probably not large enough to account for a 15-fold enhancement in E.JP amplitude.

Ouabain (0.5-1 $\mathrm{mm}$ ) has been reported to depolarize crayfish axons from 5 to $10 \mathrm{mV}$ and to reduce the action potential amplitude by $16 \mathrm{mV}$ (Wojtowicz and Atwood, 1985). In one experiment, we left the fura-injecting electrode in the presynaptic axon to measure the effect of $0.5 \mathrm{~mm}$ ouabain on presynaptic potential. The axon depolarized $7 \mathrm{mV}$ and increased the resting $\left[\mathrm{Ca}^{2+}\right]_{i}$ by $120 \pm 10 \mathrm{nM}(N=2,1)$. The action potential peak decreased by $4.2 \mathrm{mV}$, probably due to sodium ion accumulation, and the duration, measured at the base of the action potential, increased by $1.3 \mathrm{msec}$. As mentioned previously, depolarization of $13-14 \mathrm{mV}$ in this preparation leads to $\left[\mathrm{Ca}^{2+}\right]_{i}$ accumulation between 20 and $40 \mathrm{nM}$ in presynaptic terminals (Delaney et al., 1991). Therefore, the large increase in $\left[\mathrm{Ca}^{2+}\right]_{i}$ that occurs in presynaptic terminals in the presence of oubain is most likely due to an effect on $\mathrm{Na} / \mathrm{Ca}$ exchange and not calcium influx through voltage-gated calcium channels, as a 7 $\mathrm{mV}$ depolarization does not lead to detectable calcium accumulation (Delaney et al., 1991). It might be due to internal sodium accumulation releasing calcium from intracellular stores, but we measured the effect of ouabain $(0.5 \mathrm{~mm})$ in an EGTA Ringer's in five preparations and found that the resting $\left[\mathrm{Ca}^{2+}\right]_{i}$ did not change for the time it was measured (up to $100 \mathrm{~min} ; 3$ $\pm 6 \mathrm{nM} ; N=8,5$ ). To be confident that the ouabain was blocking the $\mathrm{Na} / \mathrm{K}$ pump in these zero-calcium experiments, we stopped the perfusion and watched the $\left[\mathrm{Ca}^{2+}\right]_{i}$ slowly increase by $90 \pm$ $20 \mathrm{~nm}(N=7,4)$ in $3-5 \mathrm{~min}$ and by $240 \mathrm{~nm}$ when perfusion was stopped for $30 \mathrm{~min}$ (one preparation). When perfusion with 


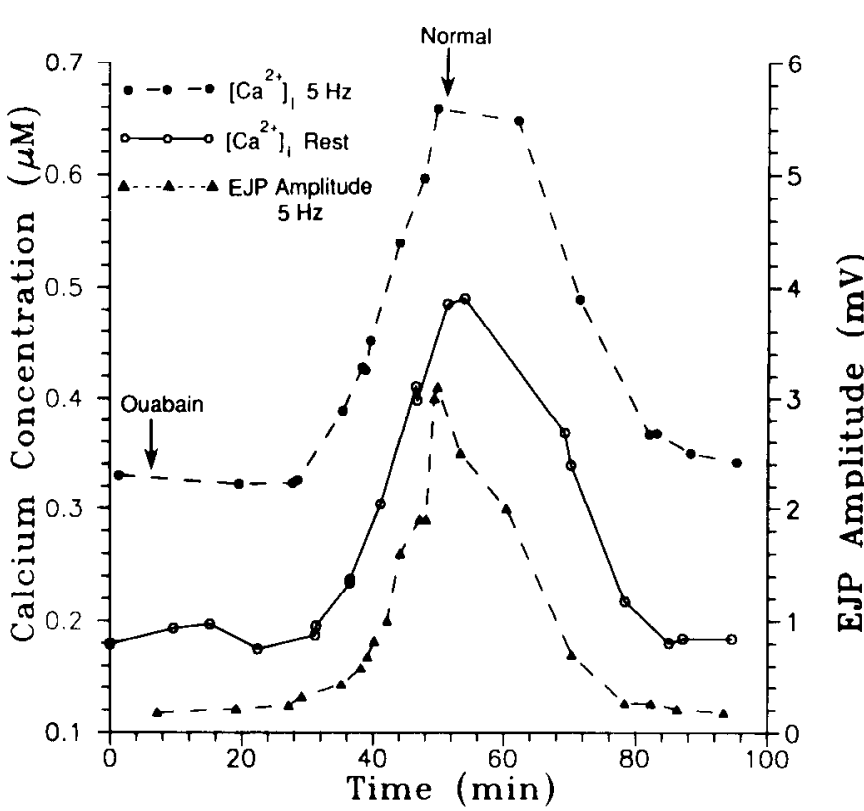

Figure 3. The effects of ouabain on $\left[\mathrm{Ca}^{2+}\right]_{i}$ and transmitter release. Ouabain $(0.5 \mathrm{~mm})$, introduced at the arrow, increased the resting $\left[\mathrm{Ca}^{2+}\right]_{i}$ (open circles) by about $300 \mathrm{nM}$, and the EJPs evoked by $5 \mathrm{~Hz}$ stimulation were increased 15 -fold (triangles). The increase in $\left[\mathrm{Ca}^{2+}\right]$, during $5 \mathrm{~Hz}$ stimulation in ouabain (solid circles) was 20-50 nM greater than the increase in $\left[\mathrm{Ca}^{2+}\right]$ during stimulation without ouabain. This indicates that the calcium influx was increased slightly by ouabain application. Removal of ouabain by washing in normal Ringer's at the second arrow brought $\left[\mathrm{Ca}^{2+}\right]_{i}$ and EJP amplitude back to preouabain values.

EGTA Ringer's was resumed, the $\left[\mathrm{Ca}^{2+}\right]_{i}$ returned to the control resting values. A ouabain application in a zero-sodium choline Ringer's (one preparation) was ineffective in elevating $\left[\mathrm{Ca}^{2+}\right]_{i}$, indicating that ouabain's effect on intracellular calcium was sodium dependent.

\section{Elevation of $\left[\mathrm{Na}^{+}\right]_{\mathrm{i}}$ by tetanic stimulation does not elevate $\mathrm{Ca}^{2+} /$;}

To test what effect a physiological sodium load had on $\left[\mathrm{Ca}^{2+}\right]_{i}$, we stimulated the excitatory axon at high frequencies (ranging from 20 to $50 \mathrm{~Hz}$ ) for 5-20 min in an EGTA Ringer's while monitoring the nerve ficld potential with an extraccllular electrode placed on a distal axonal branch to ensure action potential invasion. As shown in Figure 4, a $33 \mathrm{~Hz}, 10 \mathrm{~min}$ train had no effect on $\left[\mathrm{Ca}^{2+}\right]_{i}$, as in three other preparations ( $-8 \pm 7 \mathrm{~nm} ; N$ $=8,4)$, whereas one preparation showed a slight elevation, probably due to an insufficient wash in EGTA Ringer's (60 \pm $4 \mathrm{~nm} ; N=4,1$ ). Following the tetanus, the bathing solution was quickly changed to one containing normal calcium to see if the physiological sodium load could elevate $\left[\mathrm{Ca}^{2+}\right]_{i}$ through reversal of the $\mathrm{Na} / \mathrm{Ca}$ exchange once external calcium was available. There was no $\left[\mathrm{Ca}^{2+}\right]_{i}$ accumulation measured in all five preparations $(-2 \pm 5 \mathrm{nM} ; N=12,5)$.

To ensure that the external calcium concentration near the imaged boutons was equal to normal within $1 \mathrm{~min}$ following the tetanic train, two things were done. First, before starting the tetanic stimulation, surface terminals were selected for imaging, so solution changes would reach them quickly. Second, a stimulation, for example, $10 \mathrm{~Hz}$ for $20 \mathrm{sec}$, was initially delivered in normal Ringer's, and then EGTA Ringer's was washed in and the nerve was stimulated again; immediately afterward normal Ringer's was washed in and the nerve was stimulated a

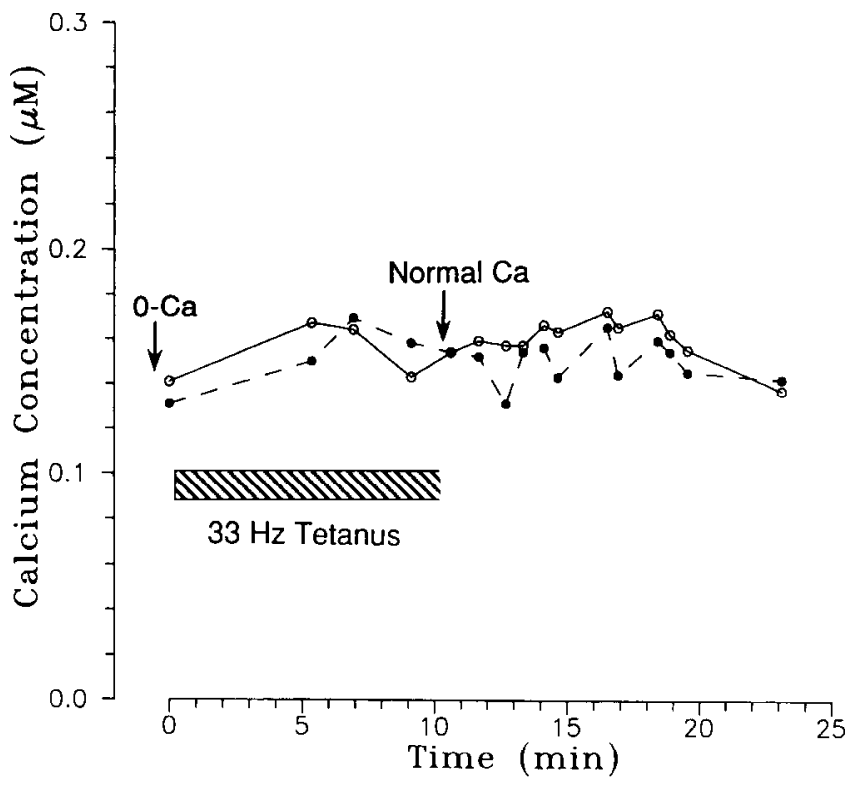

Figure 4. Sodium accumulation during high-frequency stimulation in zero-calcium Ringer's does not elevate $\left[\mathrm{Ca}^{2+}\right]_{i}$. In this preparation, $\left[\mathrm{Ca}^{2+}\right]$ was measured in two terminals, depicted by the solid and broken lines. The preparation was perfused in zero-calcium EGTA Ringer's prior to stimulation. A $10 \mathrm{~min}, 33 \mathrm{~Hz}$ tetanus was delivered, depicted by the $b a r$, and the $\left[\mathrm{Ca}^{2+}\right]_{i}$ was measured during the train. An extracellular electrode was positioned on a distal axonal branch to ensure invasion of the action potential. There was no change in the $\left[\mathrm{Ca}^{2+}\right]_{i}$ during the stimulation. Immediately following the tetanus, normal-calcium Ringer's was added, shown by the arrow, and there was no measurable change in the $\left[\mathrm{Ca}^{2+}\right]_{i}$ in either terminal.

third time 1-2 min later. In all cases the $\left[\mathrm{Ca}^{2+}\right]_{i}$ accumulation, and therefore the external calcium concentration, had reached the initial control value of the first train shortly after replacement of the EGTA Ringer's and stimulation by the third train. Apparently, sodium accumulation that occurs during a tetanus neither releases calcium from internal stores nor leads to $\left[\mathrm{Ca}^{2+}\right]_{i}$ accumulation due to reversal of the $\mathrm{Na} / \mathrm{Ca}$ exchange.

Two points must be considered before concluding that the $\mathrm{Na} / \mathrm{Ca}$ exchange did not reverse, admitting calcium from the outside. During the high-frequency stimulation in zero external calcium, little if any calcium influx occurred through calcium channels; therefore, calcium buffers and removal systems remained unsaturated. Under these conditions, perhaps some calcium influx did occur via reversal of $\mathrm{Na} / \mathrm{Ca}$ exchange once external calcium was replaced, but removal was rapid and did not lead to detectable calcium accumulation. Second, Delaney and Tank (unpublished observations), using the ratiometric fluorescent dye SBFI, measured relative $\left[\mathrm{Na}^{+}\right]_{i}$ during high-frequency stimulation ( $30 \mathrm{~Hz}, 7 \mathrm{~min}$ ) in zero-calcium, $30 \mathrm{~mm} \mathrm{Mg} \mathrm{Mg}^{2+}$ solution and showed that sodium did reach the same concentration as during stimulation in normal external solution. About 1 min after stimulation had ceased, $\left[\mathrm{Na}^{+}\right]_{i}$ fell to approximately two-thirds of its peak value reached during stimulation. $\left[\mathrm{Na}^{+}\right]_{i}$ values may have dropped below that necessary to reverse $\mathrm{Na} /$ $\mathrm{Ca}$ exchange during the $1 \mathrm{~min}$ interval needed to replace external calcium. Therefore, under conditions of high-frequency stimulation in normal external solution, it remains possible that sodium accumulation reverses $\mathrm{Na} / \mathrm{Ca}$ exchange and admits some calcium from the outside.

Another way to approach the effect of intracellular sodium would be to load terminals tetanically with sodium while phar- 


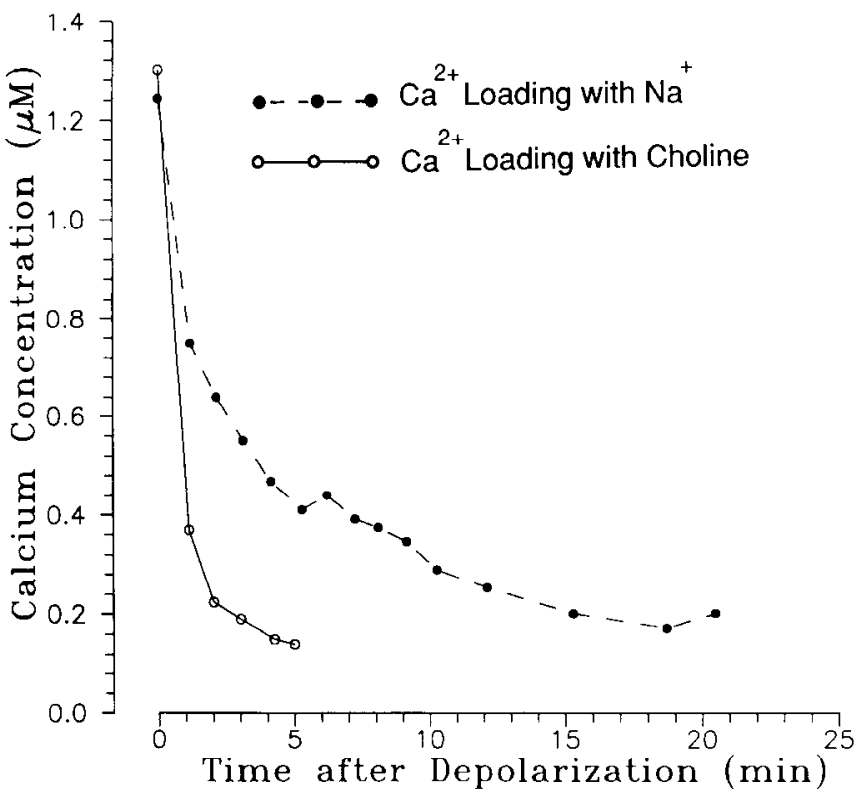

Figure 5. Loading presynaptic terminals with sodium slows the extrusion of elevated $\left[\mathrm{Ca}^{2+}\right]_{i}$. Presynaptic terminals were depolarized with high potassium $(40 \mathrm{~mm})$ to admit both sodium and calcium ions. Once $\left[\mathrm{Ca}^{2+}\right]_{i}$ had reached a criterion value $(1.3 \mu \mathrm{M})$, normal-potassium Ringer's was added and the decay of $\left[\mathrm{Ca}^{2+}\right]_{i}$ was monitored (broken line). Elevated $\left[\mathrm{Ca}^{2+}\right]_{i}$, under conditions of sodium loading, took approximately $18.5 \mathrm{~min}$ to return to the resting value. Depolarization of the terminals was repeated with a high-potassium ( $40 \mathrm{~mm}$ ) choline Ringer's, where choline was substituted for sodium. Normal Ringer's was added when the $\left[\mathrm{Ca}^{2+}\right]_{i}$ had reached the same criterion level as in the $\mathrm{Na} / \mathrm{Ca}$ loading trial. The decline of $\left[\mathrm{Ca}^{2+}\right]_{i}$ (solid line) was faster under conditions of no sodium load, taking about $4 \mathrm{~min}$ to return to the resting value.

macologically blocking calcium influx through calcium channels, and look for an effect on $\left[\mathrm{Ca}^{2+}\right]_{i}$. However, ionic blockers of calcium channels also interfere with $\mathrm{Na} / \mathrm{Ca}$ exchange (Baker and Dipolo, 1984), and we found that other calcium channel blockers ( $\omega$-conotoxin, dihydropyridines) were ineffective against calcium channels in these terminals.

\section{Elimination of sodium loading speeds the extrusion of elevated $\left[\mathrm{Ca}^{2+}\right]_{\mathrm{i}}$}

During a normal PTP-inducing train, presynaptic terminals would be loaded with both sodium and calcium ions. It is possible a sodium load could slow the calcium removal process by reducing the sodium gradient that drives the calcium extrusion via $\mathrm{Na} / \mathrm{Ca}$ exchange. Since a physiological load of intracellular sodium ions does not lead to $\left[\mathrm{Ca}^{2+}\right]_{i}$ accumulation (Fig. 4), we chose to test whether loading with both sodium and calcium would affect the rate of calcium extrusion. Preparations were depolarized with high potassium ( $40 \mathrm{~mm}$ ) to admit both sodium and calcium ions through voltage-dependent channels. The $\left[\mathrm{Ca}^{2+}\right]_{i}$ was monitored during the depolarization and the high potassium was washed out when an arbitrary criterion value for $\left[\mathrm{Ca}^{2+}\right]_{i}$ was reached. The decay of $\left[\mathrm{Ca}^{2+}\right]_{i}$ was measured while washing in normal saline. This decay time provides a measurement for calcium extrusion from the presynaptic terminal in the presence of elevated $\left[\mathrm{Na}^{+}\right]_{i}$. Preparations were then bathed in high potassium with choline substituted for sodium, while $\left[\mathrm{Ca}^{2+}\right]_{i}$ was monitored. Saline containing normal potassium and sodium was added when the $\left[\mathrm{Ca}^{2+}\right]_{i}$ had reached the same criterion level as in the sodium/calcium loading trial, and the decline in

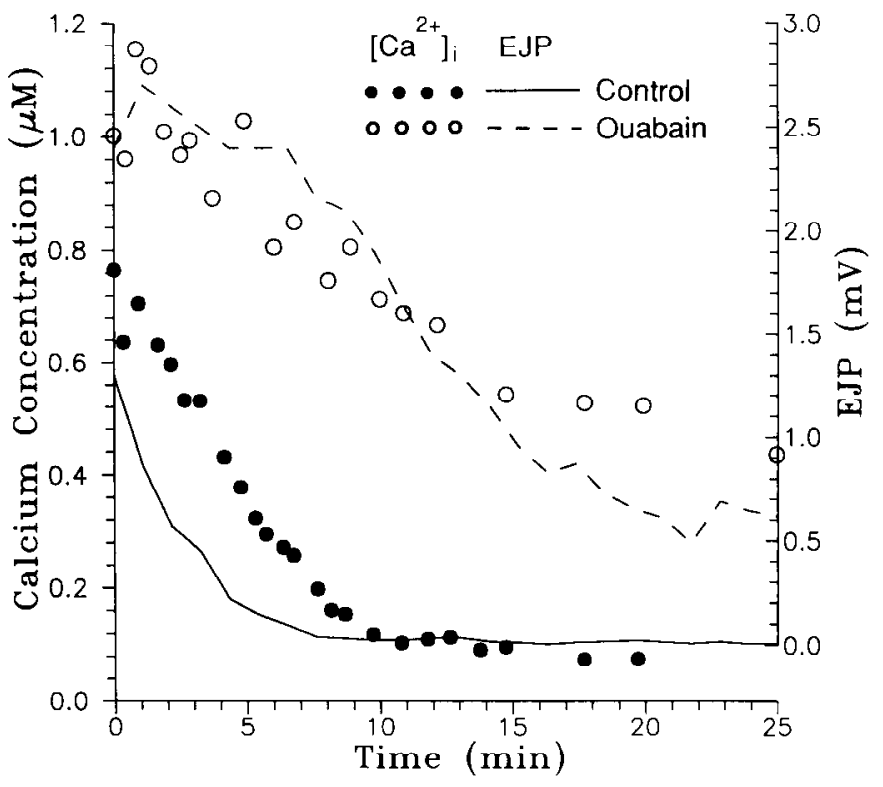

Figure 6. Increased sodium loading during a tetanus prolongs the posttetanic decay of $\left[\mathrm{Ca}^{2+}\right]_{i}$ and evoked release. A $33 \mathrm{~Hz}, 5$ min train was delivered in normal Ringer's and the posttetanic decay of EJP amplitude (solid line) and $\left[\mathrm{Ca}^{2+}\right]_{i}$ (solid circles) were measured. The time constant for posttetanic decay was calculated as $4 \mathrm{~min}$ for EJPs and about $6 \mathrm{~min}$ for $\left[\mathrm{Ca}^{2+}\right]_{i}$. Ouabain $(0.5 \mathrm{~mm})$ was added, and an identical tetanic stimulation was delivered in the same preparation. Tetanic stimulation in ouabain enhanced and prolonged EJP amplitude and $\left[\mathrm{Ca}^{2+}\right]_{i}$ during and following the tetanus, with the time constant for EJP posttetanic decay (broken line) calculated as $15.5 \mathrm{~min}$ and the decay time constant for $\left[\mathrm{Ca}^{2+}\right]_{i}$ calculated as $22 \mathrm{~min}$ (open circles).

$\left[\mathrm{Ca}^{2+}\right]_{i}$ was followed. We found (Fig. 5) that calcium extrusion was slower in the presence of elevated intracellular sodium (removal time constant of $12.3 \pm 1.8 \mathrm{~min} ; N=8,7$ ) compared to the removal of $\left[\mathrm{Ca}^{2+}\right]_{i}$ without an intracellular sodium load (time constant of $4.0 \pm 0.4 \mathrm{~min} ; N=8,7$ ). We conclude that a sodium load interferes with the extrusion of calcium, probably by reducing the sodium gradient, which in turn slows the $\mathrm{Na}$ / $\mathrm{Ca}$ exchange rate. Because action potentials are blocked in choline Ringer's, we could not record transmitter release in these experiments.

\section{Increased sodium loading during a tetanus prolongs the posttetanic decay of $\left[\mathrm{Ca}^{2+}\right]_{i}$ and evoked release}

Ouabain was used to increase the sodium loading during tetanic stimulation to test the possibility that PTP would be prolonged under these conditions. In the same preparation, posttetanic decay of EJPs and $\left[\mathrm{Ca}^{2+}\right]_{i}$ was measured following a $33 \mathrm{~Hz}, 5$ min stimulation in normal Ringer's and one that contained 0.5 mm ouabain. Ouabain was added for $40 \mathrm{~min}$ prior to the highfrequency stimulation trial, and EJPs and resting $\left[\mathrm{Ca}^{2+}\right]_{i}$ were measured to ensure both had increased (a known effect of ouabain, as mentioned previously; e.g., Fig. 3). A saline solution, with no added calcium, was washed over the preparation to reduce the ouabain-enhanced EJP to an amplitude close to that of EJPs in normal Ringer's. The resting $\left[\mathrm{Ca}^{2+}\right]_{i}$ also decreased with the addition of the low-calcium saline. Figure 6 shows the decay of $\left[\mathrm{Ca}^{2+}\right]_{i}$ and EJP amplitude following a $33 \mathrm{~Hz}, 5 \mathrm{~min}$ train in normal and ouabain Ringer's. In this experiment the time constant for decay of the EJP amplitude was $4 \mathrm{~min}$ in normal ( $4.4 \pm 0.9 \mathrm{~min} ; N=5$ ) versus $15.5 \mathrm{~min}$ in ouabain (17.3 $\pm 3.8 \mathrm{~min} ; N=5$ ). In this preparation, the $\left[\mathrm{Ca}^{2+}\right]_{i}$ decayed with 
a time constant of $5.7 \mathrm{~min}(5.8 \pm 3.6 \mathrm{~min} ; N=6,5)$ versus 22 $\min (35 \pm 7.3 \mathrm{~min} ; N=6,5)$ in normal and ouabain solutions, respectively. In the five preparations in which paired data were collected, the posttetanic decay time constant for $\left[\mathrm{Ca}^{2+}\right]_{i}$ in ouabain was significantly slower than normal $(p<0.01)$, along with a significantly slower EJP decay time constant $(p<0.02)$. From these results, it appears sodium loading augments and prolongs PTP by slowing the extrusion of calcium by $\mathrm{Na} / \mathrm{Ca}$ exchange.

During tetanic stimulation in ouabain, the $\left[\mathrm{Ca}^{2+}\right]_{i}$ reached higher values than during the control stimulation, but accurate measurements were hard to obtain as muscle contraction caused movement artifacts during fura-2 image acquisition. The EJPs became very large (i.e., $15-20 \mathrm{mV}$ ) initially and in some cases became smaller later in the stimulation, perhaps due to depression. Upon completion of the train, the averaged EJP at 1 $\mathrm{Hz}$ (in three preparations) grew for approximately 2 or $3 \mathrm{~min}$ and then decayed.

The PTP decay time constant for EJPs was faster than that of $\left[\mathrm{Ca}^{2+}\right]_{i}$ for ouabain solutions (17.3 vs $35 \mathrm{~min}$ ), but the time constants were similar in normal solution (Delaney et al., 1989). A disappearance of EJPs occurred in some preparations following the PTP-inducing train in ouabain, probably due to ouabain causing such an increase in presynaptic $\left[\mathrm{Na}^{+}\right]_{i}$ that the action potential was blocked. Balnave and Gage (1974) reported a similar disappearance of endplate potentials (EPPs) at the toad NMJ following 120 min exposure to ouabain. A gradual block of the action potential following a train could explain the faster decay of the EJP compared to the decay of $\left[\mathrm{Ca}^{2+}\right]_{i}$ in ouabain.

Blocking the $\mathrm{Na} / \mathrm{Ca}$ exchange following a tetanus prolongs the posttetanic decay of $\left[\mathrm{Ca}^{2+}\right]_{i}$

Lithium substitution for extracellular sodium is a satisfactory way to inhibit calcium efflux through $\mathrm{Na} / \mathrm{Ca}$ exchange, as lithium ions cannot replace sodium in the exchanger (Hermoni et al., 1987). A high-frequency stimulation, $33 \mathrm{~Hz}$ for $5 \mathrm{~min}$, was delivered in normal Ringer's and the $\left[\mathrm{Ca}^{2+}\right]$, decay following the train was measured. An identical PTP-inducing train was delivered, after $\left[\mathrm{Ca}^{2+}\right]_{i}$ had returned to rest from the first trial, and lithium Ringer's (lithium substituted for sodium) was washed in immediately after the stimulation ceased. Both PTP-inducing trains were delivered in normal Ringer's, with lithium Ringer's washed in only after stimulation ended, to avoid loading the terminal with lithium, as lithium is known to have cffects on intracellular second messenger systems (Berridge and Irvine, 1989).

Figure 7 shows the posttetanic decay of $\left[\mathrm{Ca}^{2+}\right]_{i}$ in normal and lithium Ringer's. The time constant of decay in normal Ringer's is equal to $6.3 \mathrm{~min}$, compared to $15 \mathrm{~min}$ for lithium Ringer's. Normal and lithium posttetanic decay of $\left[\mathrm{Ca}^{2+}\right]_{i}$ were measured in seven preparations and 13 terminals, with a mean of $6.5 \pm$ $1.4 \mathrm{~min}$ for a control decay time constant and $15.7 \pm 3.9 \mathrm{~min}$ for a decay time constant in lithium. The time constant for $\left[\mathrm{Ca}^{2+}\right]_{i}$ decay in lithium was significantly slower $(p<0.05)$.

EJPs were measured following stimulation in normal and lithium Ringer's, but lithium is known to have a depressant effect on the postsynaptic potential at the crayfish NMJ (Ortiz and Junge, 1978). This depressant effect was observed in these experiments, and therefore measurement of EJP posttetanic decay was not possible.

Upon addition of lithium Ringer's in four out of seven preparations, the $\left[\mathrm{Ca}^{2+}\right]_{i}$ jumped by $450 \pm 60 \mathrm{nM}(N=9,4)$ for the first $30 \mathrm{sec}$ to $1 \mathrm{~min}$ and then decayed, as shown in Figure 7.

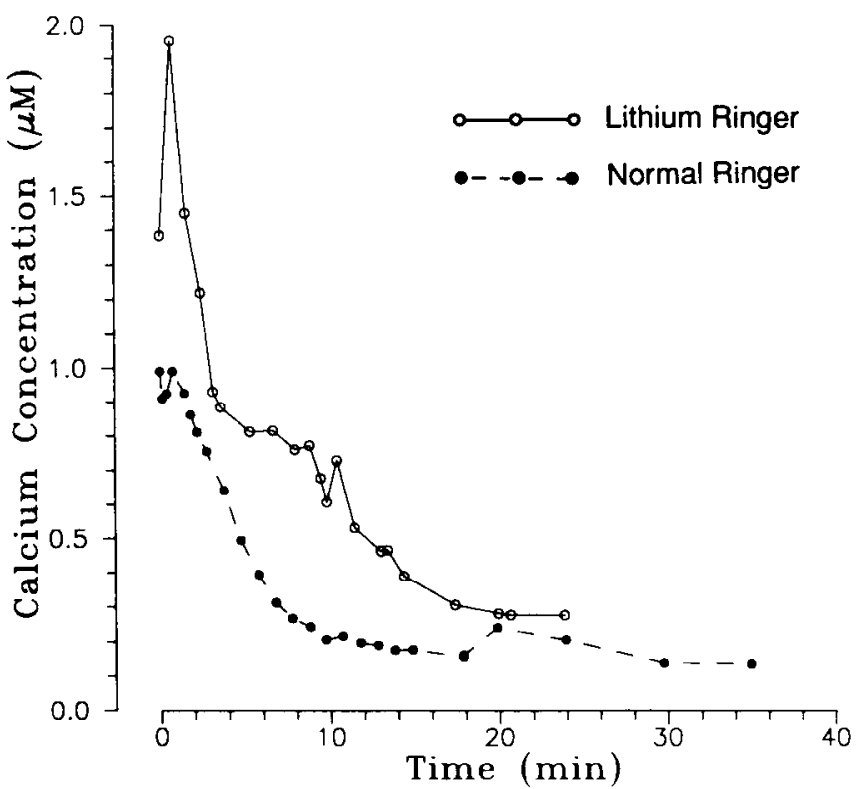

Figure 7. Blocking the $\mathrm{Na} / \mathrm{Ca}$ exchange following a tetanus with lithium prolongs the posttetanic decay of $\left[\mathrm{Ca}^{2+}\right]_{i}$. Tetanic stimulation, 33 $\mathrm{Hz}$ for $5 \mathrm{~min}$, was delivered in normal Ringer's and the decay of $\left[\mathrm{Ca}^{2+}\right]$ (broken line) was measured following the train. The time constant for decay of $\left[\mathrm{Ca}^{2+}\right]_{i}$ in normal Ringer's was equal to about $6 \mathrm{~min}$. In the same preparation, a second train was delivered in normal Ringer's. Following this tetanus, lithium Ringer's (in which lithium replaced sodium) was added and the $\left[\mathrm{Ca}^{2+}\right]_{i}$ decline was monitored (solid line). The time constant for $\left[\mathrm{Ca}^{2+}\right]_{i}$ decay was calculated to be $15 \mathrm{~min}$.

This sudden rise in $\left[\mathrm{Ca}^{2+}\right]_{i}$ may be due to a reversal in the $\mathrm{Na}$ / Ca exchange because of low external sodium and the high internal sodium. This sudden increase in intracellular calcium was also observed in one preparation, five terminals $(300 \pm 110 \mathrm{nM})$ upon washing in choline Ringer's following a PTP-inducing train. In contrast, experiments using a zero-sodium Ringer's without sodium loading showed little increase in $\left[\mathrm{Ca}^{2+}\right]_{i}$ for up to $30 \min (20 \pm 5 \mathrm{~nm} ; N=23,12)$. We conclude that when calcium efflux through $\mathrm{Na} / \mathrm{Ca}$ exchange was inhibited by using lithium, the jump in $\left[\mathrm{Ca}^{2+}\right]_{i}$ seen once high-frequency stimulation had ceased was due to the reversal of the exchanger. This reversal is only detected when $\left[\mathrm{Na}^{+}\right]_{i}$ has been elevated, followed by removal of external sodium. In addition, the posttetanic decay of $\left[\mathrm{Ca}^{2+}\right]_{i}$ was slowed by inhibiting calcium efflux through $\mathrm{Na} / \mathrm{Ca}$ exchange with lithium.

\section{Complications in using nonspecific $\mathrm{Na} / \mathrm{Ca}$ exchange blockers}

Blocking the $\mathrm{Na} / \mathrm{Ca}$ exchange during tetanic and posttetanic phases was attempted using the amiloride derivative $2^{\prime}, 4^{\prime}$-dimethylbenzamil (DMB), which has been used to block $\mathrm{Na} / \mathrm{Ca}$ exchange in smooth muscle cells (Smith et al., 1987). DMB was the generous gift of Merck, Sharp \& Dohme. Unfortunately, DMB partitioned into the cell membrane and fluoresced intensely, interfering somewhat with the fura-2 signal. However, because we had intracellularly injected fura-2, our images were bright and we were able to overcome this problem. At the high doses $(100 \mu \mathrm{M})$ reported to be effective in blocking $\mathrm{Na} / \mathrm{Ca}$ exchange (Siegl et al., 1984), DMB appeared to cause photodamage, even from a single image. When DMB was used without imaging calcium, and only EJPs were recorded, it appeared to block sodium channels in the axon, as the spike failed. DMB was used at a lower dose $(20 \mu \mathrm{M})$ and did not cause photodamage 
during fura- 2 imaging, but led to a 10 -fold increase in EJP amplitude without an increase in resting $\left[\mathrm{Ca}^{2+}\right]_{i}$. Due to the complications that arose from using DMB, we tried amiloride, at a dose ( $2 \mathrm{~mm}$ ) reported to block the $\mathrm{Na} / \mathrm{Ca}$ exchange (Kleyman and Cragoe, 1988). At this dose, we found that amiloride completely quenched the fura- 2 signal. Therefore, we chose to record only EJPs without calcium imaging and found the amiloride decreased the EJP amplitude. Amiloride has been reported to block T-type calcium channels in mouse neuroblastoma and chick dorsal root ganglion neurons at a lower dose $(500 \mu \mathrm{M})$ than needed to block the $\mathrm{Na} / \mathrm{Ca}$ exchange (Tang et al., 1988), and this could account for the decrease we saw in EJP amplitude. Thus, amiloride derivatives did not prove useful as inhibitors of $\mathrm{Na} / \mathrm{Ca}$ exchange.

\section{Discussion}

Reversal of the $\mathrm{Na} / \mathrm{Ca}$ exchange elevates $\left./ \mathrm{Ca}^{2+}\right]_{\mathrm{i}}$ when internal sodium is raised by pharmacological methods

Experimental methods that led to the elevation of internal sodium ions, that is, injection of intracellular sodium and exposure to ouabain and veratridine, increased $\left[\mathrm{Ca}^{2+}\right]_{i}$, but only if calcium ions were present in the external medium, suggesting that it was operating via $\mathrm{Na} / \mathrm{Ca}$ exchange. All three pharmacological methods have previously been used at the crayfish NMJ and other synaptic preparations. First, the injection of sodium ions intracellularly into the crayfish axon (as reported by Wojtowicz and Atwood, 1985) produced an increase in transmitter release that was long lasting in one preparation, compared to a transient increase obtained by intracellular injection of potassium ions. These experiments are in agreement with our findings that show a significantly higher elevation of $\left[\mathrm{Ca}^{2+}\right]_{i}$ during sodium injection compared to potassium injection in the crayfish axon, assuming the increase in transmitter release observed by Wojtowicz and Atwood (1985) was due to $\left[\mathrm{Ca}^{2+}\right]_{i}$ elevation in the presynaptic terminals.

Second, previous experimenters have used ouabain in various synaptic preparations and found that ouabain enhances transmitter release. At the crayfish NMJ, ouabain prolonged PTP (Atwood et al., 1975) and greatly enhanced EJP amplitude (Wojtowicz and Atwood, 1985). Prolongation of PTP was also obtained at the frog (Rahamimoff et al., 1978; Lev-Tov and Rahamimoff, 1980; Misler and Hurlbut, 1983; Misler et al., 1987) and rat NMJ (Nussinovitch and Rahamimoff, 1988). Ouabain experiments performed in zero-calcium solutions to determine mechanism of sodium elevation were done at the mammalian and frog NMJ. In agreement with our experiments were those of Elmqvist and Feldman (1965) and Vizi and Vyskocil (1979) at the mammalian NMJ, where the preparation was exposed to ouabain in a zero-calcium solution, and transmitter release, measured as frequency of MEPPs, remained unchanged compared to an increase in release when external calcium was present. It is assumed that the frequency of MEPPs reflects the resting $\left[\mathrm{Ca}^{2+}\right]_{i}$. In contrast, Baker and Crawford (1975) at the frog NMJ and Nussinovitch and Rahamimoff (1988) at the mammalian NMJ have shown that the frequency of MEPPs increased in the presence of ouabain in a zero-calcium EGTA solution and posttetanic decay of MEPP frequency was also increased. This discrepancy may be due to a difference between intracellular calcium stores at the crayfish versus the mammalian and frog NMJ. More likely, it can be attributed to an ineffective zero-calcium EGTA perfusion. In our experiments, we found ouabain to be quite effective in raising $\left[\mathrm{Ca}^{2+}\right]_{i}$ in a zerocalcium EGTA solution when our continuous perfusion was halted. The fact we could achieve a positive result in both a ouabain or a sodium injection experiment in zero-calcium medium if the EGTA rinse was not done vigorously suggests that previous experiments showed an increased frequency of MEPPs in a zero-calcium ouabain-containing medium only because calcium was still present in the extracellular space surrounding nerve terminals, where it is effectively buffered to intermediate levels (Ginsburg and Rahamimoff, 1983).

Third, experimental studies using veratridine at the crayfish NMJ conflict with our findings. We found, using the drug veratridine, that the elevation of intracellular sodium ions proved to be dependent on external calcium ions in order to raise $\left[\mathrm{Ca}^{2+}\right]_{i}$, whereas Finger and Martin (1987) and Martin and Finger (1988), using high doses of veratridine $(100 \mu \mathrm{M})$, reported an increase in spontaneous transmitter release at the crayfish NMJ in a zerocalcium medium. These investigators used no chelating agent in their zero-calcium saline, and, as it is virtually impossible to eliminate external calcium under these conditions (Mulkey and Zucker, 1991a), it is likely that intracellular calcium increased simply due to influx through voltage-gated calcium channels, known to be open at these high, depolarizing doses of veratridine (Ohta et al., 1973; Delaney et al., 1991).

\section{Posttetanic potentiation is dependent on calcium influx from the external media}

Previous experimenters have suggested that PTP is independent of calcium entry from the external medium. Nussinovitch and Rahamimoff (1988) in the mammal; Lev-Tov and Rahamimoff (1980), Misler and Hurlbut (1983), and Misler et al. (1987) in the frog; and Swenarchuk and Atwood (1975) in the crayfish showed that stimulation in a calcium-free medium produced some PTP after normal calcium was restored. Stimulation at high frequencies, like that needed to induce PTP, in a nominally calcium-free Ringer's can lead to calcium entry and even transmitter release, as shown recently at the crayfish NMJ (Mulkey and Zucker, 1991a). Therefore, it is difficult to ensure that calcium influx did not occur during stimulation in a calcium-free solution unless direct measurements of $\left[\mathrm{Ca}^{2+}\right]_{i}$ can be made. Experiments by Wojtowicz and Atwood (1988) in the crayfish showed that PTP (or the tetanic phase of LTF, as they refer to it) does not occur when high-frequency stimulation is given in solutions effective in blocking calcium influx. Since PTP is not observed under these conditions (Wotjowicz and Atwood, 1988), this suggests that sodium alone has no direct effect on transmitter release. However, since the crayfish NMJ is extremely difficult to wash free of calcium, the return of normal external calcium to all synaptic terminals (beneath muscle fibers) is also slow. This time lapse may therefore prevent the observation of a calcium-independent component to PTP. We do know, however, from fura- 2 intracellular calcium measurements that trains in calcium-blocking solutions do not lead to accumulation of $\left[\mathrm{Ca}^{2+}\right]_{i}$ during or following the train, once external calcium has been restored, ruling out the possibility of calcium release from internal stores (Fig. 4). In support of this result, Connor et al. (1986) used arsenazo III to measure $\left[\mathrm{Ca}^{2+}\right]_{i}$ during PTP in L10 cells of Aplysia, while bathing the preparation in either $4 \mathrm{~mm}$ cadmium or zero-calcium, $4 \mathrm{~mm}$ EGTA. They also observed no increase in $\left[\mathrm{Ca}^{2+}\right]_{i}$ during tetanic stimulation, but found that the EGTA solution required many washings before they recorded no change. 
Reversal of $\mathrm{Na} / \mathrm{Ca}$ exchange under physiological conditions occurs only when internal sodium is high and external sodium is low

It has been suggested PTP may be due to a reversed $\mathrm{Na} / \mathrm{Ca}$ exchange that takes place during and following tetanic stimulation (Misler and Hurlbut, 1983; Misler et al., 1987). The equation for the reversal potential for a $3: 1 \mathrm{Na} / \mathrm{Ca}$ exchanger is $3 E_{\mathrm{Na}}$ $-2 E_{\mathrm{Ca}}=E_{\mathrm{Na} / \mathrm{Ca}}$. At resting conditions with a membrane potential of $-70 \mathrm{mV}$, external sodium at $200 \mathrm{~mm}$, internal sodium at $17 \mathrm{~mm}$ (Wallin, 1967), and external calcium at $13.5 \mathrm{~mm}, \mathrm{Na} /$ $\mathrm{Ca}$ exchange should transport calcium inward as long as internal calcium is less than $500 \mathrm{~nm}$. The fact that resting calcium is less than 500 nм (Mulkey and Zucker, 1991a) indicates that some other process keeps intracellular calcium low at rest, perhaps the $\mathrm{Ca}^{2+}$ pump, known to have a higher affinity for calcium than the $\mathrm{Na} / \mathrm{Ca}$ exchanger (Blaustein, 1988). Sodium loading by electrical stimulation should also increase the inward flow of calcium via $\mathrm{Na} / \mathrm{Ca}$ exchange. If $\left[\mathrm{Ca}^{2+}\right]_{i}$ rises to $1 \mu \mathrm{M}$ and $\left[\mathrm{Na}^{+}\right]_{\text {i goes above }} 21 \mathrm{mM}$, the $\mathrm{Na} / \mathrm{Ca}$ exchange should transport calcium inward. It is known that action potential amplitude decreases during high-frequency stimulation, suggesting a significant accumulation of sodium occurring during repetitive stimulation (Wojtowicz and Atwood, 1985). $\left[\mathrm{Na}^{+}\right]_{i}$ probably rcaches values above $21 \mathrm{~mm}$ during a PTP-inducing train, since resting values have been estimated to be around $17 \mathrm{~mm}$ (Wallin, 1967). However, our evidence suggests that a net calcium influx, presumably due to a $\mathrm{Na} / \mathrm{Ca}$ exchange, is seen under physiological conditions of sodium loading only when sodium outside is low and intracellular sodium is elevated (Fig. 7). This is in agreement with work done in squid axon (Dipolo, 1979; Baker and Dipolo, 1984; Mullins et al., 1985), synaptosomes (Blaustein and Oborn, 1975), and vascular smooth muscle (Bova et al., 1990), where in all cases, calcium influx occurred only when external sodium was low.

We have looked for $\left[\mathrm{Ca}^{2+}\right]$ accumulation due to reversal of $\mathrm{Na} / \mathrm{Ca}$ exchange under two other conditions: (1) by loading sodium with tetanic stimulation in zero-calcium normal-sodium Ringer's and then restoring external calcium, and (2) in a zero-sodium bathing solution when internal sodium is low. Under neither of these conditions was $\left[\mathrm{Ca}^{2+}\right]_{i}$ accumulation detected. As mentioned previously in the results, the first experiment, high-frequency stimulation in zero external calcium, may not detect $\left[\mathrm{Ca}^{2+}\right]_{i}$ accumulation because of the time needed to replace external calcium once the stimulation has ceased. In this 1 min interval, $\left[\mathrm{Na}^{+}\right]_{i}$ had dropped to approximately two-thirds of its peak value reached during the high-frequency stimulation (Delaney and Tank, unpublished observations). Second, it is possible we could not record $\left[\mathrm{Ca}^{2+}\right]_{i}$ accumulation because of the action of calcium buffers and removal systems. An example of the effect of cell buffers on the detection of $\left[\mathrm{Ca}^{2+}\right]_{i}$ accumulation was reported in the squid axon by Swandulla et al. (1991). When the calcium buffer EGTA was injected into the presynaptic terminal, transmitter release was not affected but changes in $\left[\mathrm{Ca}^{2+}\right]_{i}$ accumulation, measured using fura-2, were eliminated. In contrast, under normal conditions, $\left[\mathrm{Ca}^{2+}\right]_{i}$ reached values of $1 \mu \mathrm{M}$. Therefore, conditions in which intracellular buffers are not saturated may affect the $[\mathrm{Ca}]_{i}$ accumulation that is measured by the fura-2. In the second group of experiments, there was no increase in $\left[\mathrm{Ca}^{2+}\right]_{i}$ detected when $\left[\mathrm{Ca}^{2+}\right]_{i}$ and $\left[\mathrm{Na}^{+}\right]_{i}$, were at resting values and external sodium was removed. Similar to the high-frequency stimulation experiment, $\left[\mathrm{Ca}^{2+}\right]_{i}$ remained at rest and buffers and removal systems were unsaturated, which may explain why calcium accumulation was not measured under these conditions. Therefore, calcium influx through $\mathrm{Na} / \mathrm{Ca}$ exchange under physiological conditions is detected using fura-2 measurements only when external sodium is low and internal sodium and calcium are elevated.

Pharmacological methods used to elevate sodium (ouabain, veratridine, and sodium injection) appeared quite successful in reversing the $\mathrm{Na} / \mathrm{Ca}$ cxchange under conditions when $\left[\mathrm{Ca}^{2+}\right]_{i}$ was at rest. This discrepancy between sodium loading by pharmacological methods and physiological methods may be the result of $\left[\mathrm{Na}^{+}\right]_{i}$ not reaching as high a value in the physiological condition. Another possibility is that perhaps ouabain and veratridine had some nonspecific effect on the calcium pump or buffering systems such that a detectable rise in $\left[\mathrm{Ca}^{2+}\right]_{i}$ was really the result of an inhibition of the calcium removal systems.

\section{Intraterminal sodium accumulation enhances and prolongs posttetanic potentiation}

We have shown that an internal sodium load slows calcium removal from the presynaptic terminal, in addition to prolonging PTP. This is evidence that sodium ions contribute to the gradual decline in $\left[\mathrm{Ca}^{2+}\right]_{i}$ following tetanic stimulation. Blocking calcium efflux via $\mathrm{Na} / \mathrm{Ca}$ exchange (by reducing the external sodium concentration with lithium substitution) prolongs the decay of $\left[\mathrm{Ca}^{2+}\right]_{i}$ and is additional support that $\mathrm{Na} / \mathrm{Ca}$ exchange may play an important role in PTP. This evidence, though it is indirect, suggests that PTP is the result of an intracellular calcium and sodium load, and that the subsequent decay of $\left[\mathrm{Ca}^{2+}\right]_{i}$ is dependent on the $\mathrm{Na} / \mathrm{Ca}$ exchange rate. Delaney and Tank (unpublished observations) have measured $\left[\mathrm{Na}^{+}\right]_{i}$ in crayfish presynaptic terminals using the fluorescent dye SBFI, and have shown that following a PTP $\operatorname{train}(33 \mathrm{~Hz}, 7 \mathrm{~min}),\left[\mathrm{Na}^{+}\right]_{i}$ decays with a time constant of around $3 \mathrm{~min}$. This is similar to the time constant of $\left[\mathrm{Ca}^{2+}\right]_{i}$ decline following a PTP train (i.e., 5.8 min reported in Results). Since we know that sodium accumulation that occurs as a result of high-frequency stimulation stays elevated for minutes following the train, it may therefore be partly responsible for the time constant of decay for $\left[\mathrm{Ca}^{2+}\right]_{i}$ following a PTP-inducing stimulus. Additional support for PTP being sodium dependent is given by experiments in crayfish in which sodium influx is blocked by TTX and trains of depolarizing pulses equivalent to action potentials in releasing transmitter were delivered through an intracellular electrode. These experiments revealed reduced PTP under conditions where sodium accumulation was prevented (Wojtowicz and Atwood, 1988).

\section{References}

Atwood HL, Wojtowicz JM (1986) Short-term and long-term plasticity and physiological differentiation of crustacean motor synapses. Int Rev Neurobiol 28:275-362.

Atwood HL, Swenarchuk LE, Gruenwald CR (1975) Long-term synaptic facilitation during sodium accumulation in nerve terminals. Brain Res 100:198-204.

Atwood HL, Charlton MP, Thompson CS (1983) Neuromuscular transmission in crustaceans is cnhanced by a sodium ionophorc, monensin, and by prolonged stimulation. J Physiol (Lond) 335:179-195.

Baker PF, Crawford AC (1975) A note on the mechanism by which inhibitors of the sodium pump accelerate spontaneous release of transmitter from motor nerve terminals. J Physiol (Lond) 247:209-226.

Baker PF, Dipolo R (1984) Axonal calcium and magnesium homeostasis. Curr Top Membr Transport 22:195-247. 
Balnave RJ, Gage PW (1974) On facilitation of transmitter release at the toad neuromuscular junction. J Physiol (Lond) 239:657-675.

Berridge MJ, Irvine RF (1989) Inositol phosphates and cell signalling. Nature 341:197-205.

Blaustein MP (1988) Calcium transport and buffering in neurons. Trends Neurosci 11:438-443.

Blaustein MP, Oborn CJ (1975) The influence of sodium on calcium fluxes in pinched-off nerve terminals in vitro. J Physiol (Lond) 247: $657-686$.

Bova S, Goldman WF, Yuan X, Blaustcin MP (1990) Influcnce of $\mathrm{Na}^{+}$gradient on $\mathrm{Ca}^{2+}$ transients and contraction in vascular smooth muscle. Am J Physiol 259:H409-H423.

Catterall WA (1980) Neurotoxins that act on voltage-sensitive sodium channels in excitable membranes. Annu Rev Pharmacol Toxicol 20: $15-43$.

Charlton M, Atwood HL (1977) Modulation of transmitter release by intracellular sodium in squid giant synapse. Brain Res 134:367-371.

Connor JA, Kretz R, Shapiro E (1986) Calcium levels measured in a presynaptic neurone of Aplysia under conditions that modulate transmitter release. J Physiol (Lond) 375:625-642.

Delaney KR, Zucker RS, Tank DW (1989) Calcium in motor nerve terminals associated with posttetanic potentiation. J Neurosci 9:35583567.

Delaney K, Tank DW, Zucker RS (1991) Presynaptic calcium and serotonin-mediated enhancement of transmitter release at crayfish neuromuscular junction. J Neurosci 11:2631-2643.

Dipolo $R$ (1979) Calcium influx in internally dialyzed squid giant axons. J Gen Physiol 73:91-113.

Elmqvist D, Feldman DS (1965) Calcium dependence of spontaneous acetylcholine release at mammalian motor nerve terminals. J Physiol (Lond) 181:487-497.

Finger W, Martin C (1987) Differential effect of intraterminal sodium on spontaneous quantal release of transmitter in two neuromuscular junctions of crayfish. Neurosci Lett 75:293-298.

Ginsburg S, Rahamimoff R (1983) Is extracellular buffering involved in regulation of transmitter release at the neuromuscular junction? Nature 306:62-64.

Grynkiewicz GM, Pocnic M, Tsien RY (1985) A new generation of $\mathrm{Ca}^{2+}$ indicators with greatly improved fluorescence properties. J Biol Chem 260:3440-3450.

Hermoni M, Barzilai A, Rahamimoff H (1987) Modulation of the Na$\mathrm{Ca}$ antiport by its ionic environment: the effect of lithium. Isr J Med Sci 23:44-48.

Kao JP, Tsien RY (1988) Calcium binding kinetics of fura-2 and azo-1 from temperature-jump relaxation measurements. Biophys J 53:635639.

Katz B (1969) The release of neural transmitter substances. Springfield, IL: Thomas.

Kleyman TR, Cragoe EJ Jr (1988) Amiloride and its analogs as tools in the study of ion transport. J Membr Biol 105:1-21.

Lev-Tov A, Rahamimoff R (1980) A study of tetanic and post-tetanic potentiation of miniature end-plate potentials at the frog neuromuscular junction. J Physiol (Lond) 309:247-273.

Martin C, Finger W (1988) Veratridine-induced high-frequency asynchronous release of inhibitory transmitter quanta in crayfish nervemuscle synapses superfused with normal and low-calcium saline. Pfluegers Arch 411:469-477.

Meiri H, Erulkar SD, Lerman T, Rahamimoff R (1981) The action of the sodium ionophore, monensin, on transmitter release at the frog neuromuscular junction. Brain Res 204:204-208.

Misler S, Hurlbut WP (1983) Post-tetanic potentiation of acetylcholine release at the frog neuromuscular junction develops after stimulation in $\mathrm{Ca}^{2+}$-free solutions. Proc Natl Acad Sci USA 80:315-319.
Misler S, Falke L, Martin S (1987) Cation dependence of posttetanic potentiation of neuromuscular transmission. Am J Physiol 252:C55C62.

Mulkey RM, Zucker RS (1991a) Action potentials must admit calcium to evoke transmitter release. Nature 350:153-155.

Mulkey RM, Zucker RS (1991b) The role of $\mathrm{Ca}^{2+}$ and $\mathrm{Na}^{+}$in posttetanic potentiation at the crayfish neuromuscular junction. Soc Neurosci Abstr 17:1325.

Mullins LJ, Requena J, Whittembury J (1985) $\mathrm{Ca}^{2+}$ entry in squid axons during voltage-clamp pulses is mainly $\mathrm{Na}^{+} / \mathrm{Ca}^{2+}$ exchange. Proc Natl Acad Sci USA 82:1847-1851.

Negulescu PA, Machen TE (1990) Intracellular ion activities and membrane transport in parietal cells measured with fluorescent probes. Methods Enzymol 192:38-81.

Nussinovitch I, Rahamimoff R (1988) Ionic basis of tetanic and posttetanic potentiation at a mammalian neuromuscular junction. J Physiol (Lond) 396:435-455.

Ohta M, Narahashi T, Keeler RF (1973) Effects of veratrum alkaloids on membrane potential and conductance of squid and crayfish giant axons. J Pharmacol Exp Ther 184:143-154.

Ortiz C., Junge D (1978) Depressant action of lithium at the crayfish neuromuscular junction: pre- and postsynaptic effects. J Exp Biol 75: 171-187.

Rahamimoff R, Erulkar SD, Lev-Tov A, Meiri H (1978) Intracellular and extracellular calcium ions in transmitter release at the neuromuscular synapse. Ann NY Acad Sci 307:583-597.

Rahamimoff R, Lev-Tov A, Meiri H (1980) Primary and secondary regulation of quantal transmitter release: calcium and sodium. J Exp Biol 89:5-18.

Siegl PKS, Cragoe EJ Jr, Trumble MJ, Kaczorowski GJ (1984) Inhibition of $\mathrm{Na}^{+} / \mathrm{Ca}^{2+}$ exchange in membrane vesicle and papillary muscle preparations from guinea pig heart by analogs of amiloride. Proc Natl Acad Sci USA 81:3238-3242.

Smith JB, Cragoe EJ Jr, Smith L (1987) $\mathrm{Na}^{+} / \mathrm{Ca}^{2+}$ antiport in cultured arterial smooth muscle cells. J Biol Chem 262:1 1988-11994.

Swandulla D, Hans M, Zipser K, Augustine GJ (1991) Role of residual calcium in synaptic depression and posttetanic potentiation: fast and slow calcium signaling in nerve terminals. Neuron 7:915-926.

Swenarchuk LE, Atwood HL (1975) Long-term synaptic facilitation with minimal calcium entry. Brain Res 100:205-208.

Tang C, Presser F, Morad M (1988) Amiloride selectively blocks the low threshold (T) calcium channel. Science 240:213-215.

Vizi ES, Vyskocil F (1979) Changes in total and quantal release of acetylcholine in the mouse diaphragm during activation and inhibition of membrane ATPase. J Physiol (Lond) 286:1-14.

Wallin BG (1967) Intracellular ion concentrations in single crayfish axons. Acta Physiol Scand 70:419-430.

Wojtowicz JM, Atwood HL (1984) Presynaptic membrane potential and transmitter release at the crayfish neuromuscular junction. $J$ Neurophysiol 52:99-113.

Wojtowicz JM, Atwood HL (1985) Correlation of presynaptic and postsynaptic events during establishment of long-term facilitation at crayfish neuromuscular junction. J Neurophysiol 54:220-230.

Wojtowicz JM, Atwood HL (1988) Presynaptic long-term facilitation at the crayfish neuromuscular junction: voltage-dependent and iondependent phases. J Neurosci 8:4667-4674.

Zucker RS (1989) Short-term synaptic plasticity. Annu Rev Neurosci 12:13-31.

Zucker RS, Delaney KR, Mulkey RM, Tank DW (1991) Presynaptic calcium in transmitter release and post-tetanic potentiation. Ann NY Acad Sci 635:191-207. 